\title{
DESIGN SONORO NO RPG DE MESA: UMA ESTRATÉGIA PARA IMERSÃO
}

Nícolas de Oliveira Ribas

Faculdade Fucapi

nicolasribas91@gmail.com

Narle Silva Teixeira

Faculdade Fucapi

narle163@gmail.com

Resumo: Aquela música preferida, a voz de alguém que se ama, o som de relâmpagos em uma tempestade ou de um tiro de revólver. Esses são alguns dos inúmeros exemplos de sons que podem despertar memórias e emoções no corpo. Considerando esse contexto, o artigo apresenta o processo e o resultado da investigação da utilização do som no RPG de mesa para uma experiência de jogo mais imersiva. Para atingir o objetivo, seguiu-se um processo sistemático anteriormente planejado e uma pesquisa realizada com um grupo de jogadores assíduos. As Teorias do campo do Design Sonoro e do Game Design fundamentaram a pesquisa e os resultados apontaram para uma maior imersão, trazendo uma melhoria considerável para o jogo.

Palavras-chave: RPG, Imersão, Design Sonoro, Game Design.

Abstract: One favorite music, the voice of someone who loves, the sound of lightning in a storm or a shot of revolver. These are some of the countless examples of sounds that can wake memories and emotions in the body. Whereas this context, this article presents the process and the outcome of the investigation of the use of sound in tabletop RPG to a more immersive gaming experience. To reach the objective, was followed by a systematic process previously planned and a research with a group of players assiduous. The theories of the field of Sound Design and Game Design motivated the search and the results pointed to a greater immersion, bringing a considerable improvement to the game.

Keywords: RPG, Immersion, Sound Design, Game Design. 


\section{INTRODUÇÃO}

O som é um fenômeno físico que se propaga tridimensionalmente pelo espaço e apenas em meios materiais, como o ar ou a água. O som está em volta do ser humano o tempo todo, atingindo, dialogando, sendo usado como meio de comunicação e emoção.

Uma música que tocou na cena mais emocionante de um filme ou de jogo digital, o som do motor de um carro correndo, um vidro quebrando, a voz de alguém conhecido, são alguns dos inúmeros exemplos de sons que podem despertar memórias e emoções em nosso corpo.

Em uma partida de RPG de mesa essa situação não seria diferente, já que é jogo em que as pessoas interpretam seus personagens, criando narrativas, histórias e um enredo guiado por uma delas, que geralmente leva o nome de mestre do jogo.

Normalmente as aventuras de RPG são apenas narradas por uma pessoa e o único som que se ouve é a voz do narrador (mestre do jogo), onde o jogador procura imaginar o cenário que para ele é descrito.

Schullian e Schoen (1948, p. 270-271) explicam que a música é capaz de nos afetar, mesmo sem que a letra seja sequer percebida:

Música, que não depende das funções superiores do cérebro para franquear entrada ao organismo, ainda pode excitar por meio do tálamo - o posto de intercomunicação de todas as emoções, sensações e sentimentos. Uma vez que um estímulo foi capaz de alcançar o tálamo, o cérebro superior é automaticamente invadido, e, se o estímulo é mantido por algum tempo, um contato íntimo entre o cérebro superior e o mundo da realidade pode ser desta forma estabelecida.

A proposta deste trabalho é fazer um estudo sobre a presente questão tendo como objetivo principal verificar se a utilização do som no RPG tornaria a experiência do jogador mais imersiva, identificando elementos que poderiam ser transformados em mídias auditivas; aplicando-os e observando a reação dos jogadores para, por fim, analisar e discutir os efeitos que o som poderá causar na jogabilidade.

Diante do exposto, o problema apresentado aponta para um campo de estudo com várias possibilidades para o designer enquanto projetista de experiências, que é a relação semiótica entre som, narração e atuação no contexto dos Jogos RPG.

\section{DESENVOLVIMENTO}

\subsection{0 que é o RPG?}

RPG é uma sigla em inglês de Role Playing Game que pode ser traduzido como Jogo de Interpretação de Papéis ou Jogo de Interpretação de Personagens. É um estilo de jogo fantasioso que utiliza a imaginação e que envolve a interpretação, ou seja, uma brincadeira narrativa, que também abrange a intenção social e aspectos dos jogos de estratégia, sendo que os resultados das ações dos jogadores são decididos nos arremessos de dados.

Os jogadores criam seus próprios personagens que, dependendo da estória, podem se desenvolver e evoluir a cada aventura concluída. Um dos jogadores será o 
Mestre, responsável por criar as aventuras, controlar os inimigos, descrever o ambiente e julgar as ações dos jogadores com base nas regras.

\subsection{História do RPG}

Segundo Finch (2009), o RPG surgiu em 1974 com a parceria de Gary Gygax (1938 - 2008) e Dave Arneson (1947 - 2009) que escreveram o primeiro e mais famoso jogo de interpretação de fantasia do mundo, o Dungeons \& Dragons (D\&D), um conjunto simples e flexível de regras, publicado inicialmente pela TSR, Inc. Hoje o jogo é publicado pela Wizards of the Coast.

Sobre o nascimento do RPG, Pavão (2000) ressalta que "o RPG surgiu de uma ideia que começou nos EUA, como evolução dos jogos de guerra e muito influenciado pela literatura de Tolkien, e que se espalhou pelo mundo rapidamente".

No Brasil, Sales (2016) afirma que o RPG chegou na década de 80 por meio da "Geração Xerox", onde os estudantes universitários importavam alguns livros e fotocopiavam para os amigos. Alguns anos depois, em 1991, foi criado Tagmar com o honroso título de "10 RPG brasileiro" publicado pela GSA. Tagmar foi um RPG típico do início dos anos 90, mas trazia uma série de novidades sendo que a principal era ter tudo que um RPG precisava em um único livro; regras, ambientação, magias, criaturas e uma aventura pronta. Na época, os RPGs eram importados e era necessário ter vários livros para jogá-los.

Tagmar virou um sucesso e durou até quase o fim dos anos 90, quando em 1997 a editora GSA fechou, e ficando assim estagnado. Porém em setembro de 2004, os autores de Tagmar se reuniram e decidiram liberar os direitos comerciais do RPG, desde que não fosse para fins lucrativos. Com esta autorização em mãos, um grupo de pessoas se reuniu e decidiu criar uma nova versão do Tagmar. Nascia assim o Projeto Tagmar 2.

Em 2006, já com a liberação dos direitos comerciais do RPG, outros sistemas foram surgindo, adaptados do cenário de Tagmar, o primeiro escolhido foi o Sistema Daemon da Daemon Editora. Em fevereiro de 2007, é anunciado o projeto de adaptar Tagmar para o Sistema d20. No site oficial também há adaptações para GURPS, Mutants \& Masterminds, publicado no Brasil pela Jambô Editora como Mutantes \& Malfeitores, e Dungeon World, em 2011, foi publicada a aventura em e-book O Casamento, uma adaptação do cenário de Tagmar para Old Dragon.

\subsection{0 que é preciso para jogar?}

Como já mencionado, é um jogo verbal fantasioso onde todas as ações se passam na imaginação dos participantes e que envolve a interpretação.

De acordo com Cook, Tweet e Willian (2004) os jogadores necessitam do seguinte:

- Do Livro do Jogador, um dos livros suplementos, onde contém todas as regras para criação de personagens, detalhando suas habilidades físicas e intelectuais, perfil psicológico, virtudes e defeitos, escolher seus equipamentos e envolvêlos em combates; o Livro do Mestre, inclui diretrizes e tudo que um Mestre precisa para criar desafios, aventuras e campanhas inteiras, incluindo itens mágicos e recompensas para os jogadores; e do Livro dos Monstros, que apresenta centenas de criaturas e versões mais poderosas delas, além de regras para criação de novos monstros.

- Uma cópia da planilha de personagem inclusa no final do Livro do Jogador. 
- Uma matriz de combate, inclusa no Livro do Mestre.

- Algumas miniaturas para representar cada personagem e os monstros que enfrentam.

- Um conjunto de dados de quadro faces (d4), seis faces (d6), oito faces (d8), dez faces (d10), doze faces (d12) e vinte faces (d20).

- Lápis, borracha, papel quadriculado e rascunhos para fazer anotações e mapear os locais que serão explorados.

Porém, nem sempre é preciso tudo isso para jogar. As vezes o Mestre cria seu próprio sistema de regras, apresenta aos jogadores, e o mínimo necessário na mesa seria uma planilha, os dados e o material para rascunhos e anotações.

A aventura proposta pelo Mestre deve conter enigmas, charadas e situações que exigirão escolhas por parte dos jogadores. Diferente dos teatros, livros e filmes, no RPG a aventura é apenas esboçada pelo Mestre, ela desenvolve-se durante o seu desenrolar, tomando rumos determinados pelas decisões dos jogadores.

\subsection{Design Sonoro nos jogos}

Aquela música emocionante que lhe chamou atenção no filme ou em um game, o ruído de um carro, vidro quebrando, explosões, lasers, barulho de dinossauro. Existe um profissional que manipula esses sons, fazendo com que cada cena tenha um efeito sobre o espectador, e esse profissional é o Sound Designer.

De acordo com Berchmans (2008, p. 162), sound design é:

[..] a criação, manipulação e organização de elementos sonoros. É o processo que reproduz o rugir de um dinossauro rex, ou o som de uma arma-laser, o tiroteio de uma sangrenta batalha, ou ainda, a voz de um computador futurista.

O design sonoro, segundo Abreu (2013), surgiu no cinema, antes mesmo da informática, com o aparecimento do sintetizador na década de 60, um instrumento musical eletrônico projetado para produzir sons gerados artificialmente usando diversas técnicas como distorção de ondas. Com isso, alguns cineastas viram a oportunidade de produzir sons artificias para seus filmes.

A primeira vez que o termo sound design apareceu nos créditos de um filme foi em Apocalipse Now (1975), do diretor Francis Ford Coppola. Graças às emergentes possibilidades técnicas da época e a busca de novos caminhos para o som do cinema, este filme marcou a fase em que o som ganhou uma importância especial no cinema. De lá pra cá, houve uma evolução sonora absurda, e hoje temos sound design em todo tipo de comunicação audiovisual além do cinema, como televisão, videogames, internet etc. (BERCHMANS, 2008, p. 161).

Em uma narrativa de RPG de mesa não seria diferente. Muitas vezes, com a falta de um som mais elaborado, os jogadores usam sua imaginação e produzem os efeitos sonoros com suas bocas, como o barulho de um tiro, explosões, a arrancada de um carro, ou usando o que tiver ao seu redor para batidas de portas, passos de pessoas correndo etc. A criação dessas séries de ruídos também é uma peculiaridade do sound design. 
Outra faceta do sound design são os Efeitos Sonoros, ou Sound Effects (SFX). Todos os sons criados com o objetivo de destacar movimentos e ações, facilitar o entendimento de uma cena, valorizar sensações ou simplesmente enriquecer a linguagem visual de um filme são atribuições dos técnicos de SFX. [...] De acordo com o tamanho da produção, às vezes a criação de efeitos sonoros é dividida em duas: efeitos editoriais e feitos principais. Os efeitos editoriais são os eventos que exigem menos complexidade de manipulação, como, por exemplo, batidas de portas, ruídos de veículos, campainhas, máquinas etc. Efeitos principais são os que envolvem um trabalho mais profundo de pesquisa e criação, como o som de dinossauros, lasers, naves, terremotos, movimentos de câmera especiais, computadores etc. (BERCHMANS, 2008, p. 162, 163).

Fora os ruídos dos efeitos sonoros criados pelo sound designer, há também a criação do valor auditivo da ambientação de uma cena, chamado de background. São sons contínuos, como o som do interior de uma nave espacial, uma fábrica em horário de trabalho, uma noite chuvosa, um escritório, "enfim, como o próprio nome diz, é a parte do áudio do filme que 'ambienta' a ação" (BERCHMANS, 2008, p. 163).

Durante o gameplay, Oliveira (2002) explica que o sound designer trabalha em várias camadas que se sobrepõem no ato de jogar, camadas essas que vão interagir umas com as outras para determinar o desenvolvimento do projeto.

Camada 0 - Som Ambiente: o som ambiente é composto pelos vários sons associados a cada seção região dentro do jogo. Exemplo: sons de chuva e ventos fortes.

Camada 1 - Som Ambiente Incidental: é aquele disparado por um evento/ação do jogador, geralmente tem curta duração e enfatiza algum aspecto daquele evento. Exemplo: tiros e explosões.

Camada 2 - Sons dos Personagens e Interface: os personagens e elementos de cenários do jogo tem sons próprios que servem para caracterizá-los. Exemplo: respiração, máquinas, sons da interface/ avisos.

Camada 3 - Música: é a camada que contém a trilha musical do jogo.

Camada 4 - Narração: é a camada dedicada às falas dos personagens e do narrador.

Todas essas camadas juntas formam a trilha sonora de um jogo que deve causar uma experiência prazerosa ao jogador. Lembrando que cada projeto especifica suas camadas à sua maneira, aqui foi apresentada apenas uma forma geral de como podem ser organizadas.

\subsection{Game Design e a imersão nos jogos}

Pode-se encontrar muitas definições sobre game design, mas como esse não é o principal foco da pesquisa, podemos considerar uma simples asserção de Schell (2008) em que ele afirma tratar-se do ato de decidir o que um jogo deveria ser. Brathwaite (2009), complementa que um bom game designer precisa criar objetivos para que os jogadores se sintam motivados a alcançar e regras que os mesmos precisam seguir ao fazer escolhas relevantes em benefício desses objetivos.

Schell (2008) afirma ainda que um game designer não cria jogos, cria experiências. E são essas experiências que definem se o jogo é bom ou não, onde é 
possível haver uma experiência multissensorial por meio de mundos virtuais ou imaginativos. Somados à maneira como são oferecidos ao jogador, esse conjunto de sentimentos classifica-se como imersão.

Para Murray (1997, p. 98-99), imersão refere-se à "sensação de estar cercado por outra realidade (...) que toma toda a nossa atenção, todo o nosso aparato perceptual".

É claro que que a imersão não surgiu com os jogos, ela já vem sendo estudada há tempos por vários pesquisadores e profissionais de outros campos, como a literatura, o cinema e, a partir da segunda metade do século $X X$, a realidade virtual. Mas é nesse campo que ela vem ganhando cada vez mais destaque com a ânsia dos desenvolvedores de tornar os jogos mais e mais realistas.

Esta pesquisa limita-se apenas em investigar a influência do som como um processo imersivo vivenciados pelos jogadores de RPG de Mesa.

Para esta pesquisa, usou-se os três tipos de imersão denominados por Ermi e Mäyrä (2005), voltados especificamente para os processos imersivos nos videogames. São eles:

- Imersão imaginativa (imaginative immersion): relacionado ao envolvimento do jogador com o conteúdo narrativo e representativo do jogo;

- Imersão baseada em desafios (challenge-based immersion): como o nome já diz, baseado em desafios, relacionado ao envolvimento do jogador quando defrontado com desafios lúdicos intrínsecos ao jogo, como solução de puzzles, estratégias para derrotar inimigos, etc;

- Imersão sensorial (sensory imersion): por último, este estaria intimamente relacionado com a pesquisa sendo referente às sensações audiovisuais e táteis proporcionadas pelo jogo.

Apesar do RPG estudado nesta pesquisa não possuir um console físico, ele usa bastante da imaginação dos jogadores por se tratar de um jogo narrado por pessoas. Por ser um jogo, pode-se usar definições citadas acima fazendo as alterações necessárias, mesmo que sejam determinados para videogames.

\section{METODOLOGIA DE INVESTIGAÇÃO PRÁTICA}

Para a realização deste trabalho seguiu-se um processo sistemático anteriormente planejado e que se apresenta de acordo com os objetivos específicos traçados para a pesquisa.

Para identificar os elementos da narrativa e transformá-los em mídias auditivas, primeiro foi feita uma pesquisa bibliográfica para se certificar dos conceitos técnicos e teóricos utilizados no trabalho, com especial atenção ao que tange as mídias auditivas. Em seguida, realizou-se uma observação participante de uma narrativa de RPG.

Gerhardte e Silveira (2009, p.75), explicam que na observação participante o pesquisador participa até certo ponto como membro do grupo. A ideia de sua incursão no grupo é ganhar a confiança do mesmo, ser influenciado pelas características dos elementos do grupo e, ao mesmo tempo, conscientizá-los da importância da investigação.

A técnica de observação participante ocorre pelo contato direto do pesquisador com o fenômeno observado e os itens observados são organizados posteriormente, numa avaliação global. A observação fez uso do seguinte roteiro: 
- Som ambiente;

- Som ambiente incidente;

- Sons dos personagens;

- Músicas que poderiam se encaixar na estória.

$\mathrm{Na}$ observação foram utilizados papel e caneta para anotar os dados. Essa primeira observação permitiu elencar os tipos de sons que poderiam ser utilizados no jogo, possibilitando que fossem produzidos para uso nas observações posteriores (narrativas sonorizadas), resultando em:

- Armas de fogo: revólveres, rifles, metralhadoras, granadas.

- Ambiente: de fábricas, tráfegos de carros, chuva.

- Colisões: de carros, vidro quebrando, corpo apanhando.

- Emergência: Ambulância, Policia.

- Humanas: vozes, gritos, respiração, passos.

- Músicas para momentos: tensos, alegres, tristes.

- Transportes: carros, dirigível, trem.

No segundo e terceiro objetivos foram feitas duas observações já com as mídias auditivas preparadas para serem usadas, uma participante e outra não-participante, que de acordo com Gerhardte e Silveira (2009, p.74), o pesquisador não se integra ao grupo observado, permanecendo de fora, presencia o fato, mas não participa dele, não se deixa envolver pelas situações, faz mais o papel de espectador.

A necessidade de haver dois tipos de observação, foi ver se teria alguma diferença nos dados coletados. O que se esperou com as observações foi perceber se com o som houve algum tipo de mudança no comportamento dos participantes, como comportamento físico, expressão facial, modo de analisar as situações do jogo etc.

Vale ressaltar que apesar das mídias auditivas estarem preparadas para o uso, elas foram usadas no improviso, pois a essência do RPG é o improviso. Apesar de haver aplicativos para sonorização, estes não serviram para a pesquisa, pois não atendiam a total necessidade, e por isso foram usados softwares de músicas no notebook para sonorizar manual das partidas.

O sistema de RPG utilizado nas partidas foi um criado pelos próprios jogadores intitulado de HEX, baseado nos sistemas de Storyteller e Savage Worlds. A temática das partidas foi num universo Steampunk, um subgênero de ficção científica onde a tecnologia a vapor desenvolveu-se até níveis impressionantes.

Por último, foi elaborado um questionário (vide figura 01 do Apêndice A) de perguntas abertas e fechadas para os participantes dissertarem suas experiências. Além das questões, consta no questionário uma escala subjetiva de percepção de imersão que de forma direta e sucinta indica a experiência do usuário. 


\section{Sonorização no RPG}

Formulário destinado ao estudo de caso para desenvolvimento de um TCC

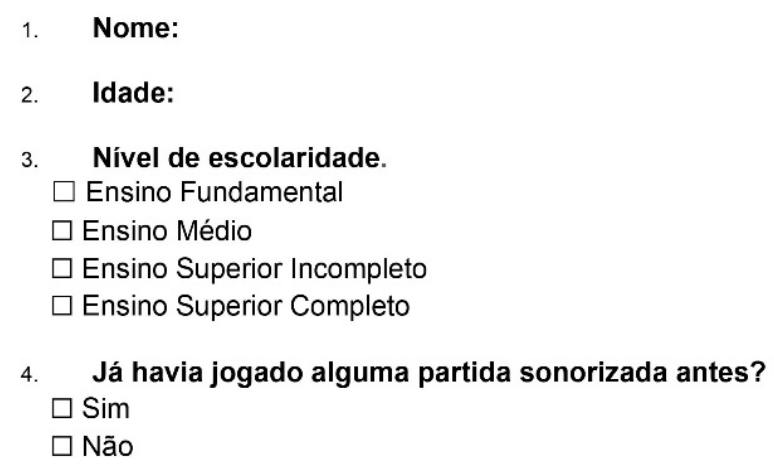

5. A partir da experiência de hoje, descreva como foi jogar com a sonorização.

6. Agora descreva como era jogar sem a sonorização, fazendo uma leve comparação com a questão anterior.

7. Indique momentos em que o som na narrativa:

a) Foi mais importante;

b) Não fez diferença;

c) Piorou o momento.

8. Dê uma classificação geral sobre a experiência da partida de hoje. Acha que teve uma imersão melhor no jogo?
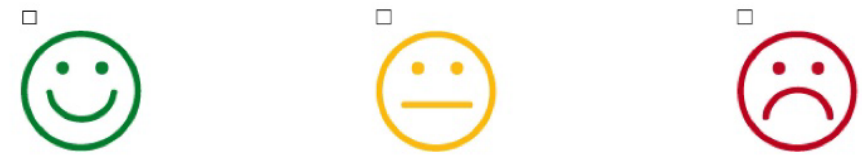

* rosto triste e vermelho significará que o som não proporcionou imersão nenhuma; o rosto normal e amarelo, que o som não teve tanto impacto, tanto faz ter som ou não; e o feliz e verde, que o participante teve uma experiência melhor no jogo, tendo uma imersão maior.

Figura 1 - Questionário limpo

Fonte: Elaborado pelo autor, com base na pesquisa realizada

$\mathrm{Na}$ escala subjetiva de imersão os participantes poderiam marcar uma das três opções para classificar a partida: rosto triste e vermelho - o som não proporcionou imersão nenhuma; rosto normal e amarelo - o som não teve tanto impacto (tanto faz ter som ou não); e feliz e verde - o participante teve uma experiência melhor no jogo, tendo uma imersão maior.

$\mathrm{Na}$ primeira observação, a participativa, foram três jogadores, incluindo o mestre (narrador), e todos responderam ao questionário. Para a segunda observação, a não-participante, foram quatro jogadores, porém só três responderam, pois o outro era o mestre que já havia narrado e participado da outra sessão. Os questionários foram enviados e devolvidos por e-mail.

\section{RESULTADOS}

Na pesquisa realizada, a partir da participação de seis jogadores, obtivemos os seguintes resultados: 
Todos os jogadores afirmaram que a sonorização do RPG, no momento em que jogavam, trouxe uma melhoria considerável para o jogo. Indicaram ter tido uma experiência muito mais imersiva na estória narrada para eles, facilitando uma visualização, vivência e ambientação maior de seus personagens, além de ficarem mais focados no jogo.

O mestre (narrador) das duas partidas assegura que:

“Com a Sonorização foi possível sentir a emoção de algumas cenas, isso fez com que todos ficassem focados no que estava acontecendo, além de facilitar a visualização da narrativa".

Quando questionados sobre como era jogar sem a sonorização, todos afirmavam que tinham uma certa dificuldade de se aprofundar no seu personagem e que o jogo ficava, por vezes, monótono. Essa questão pode ser ilustrada pela resposta de um dos participantes, que por ser formado em psicologia, tem uma visão mais crítica da situação:

"Quando jogávamos sem sonorização notava que havia algumas dificuldades que eram: o tempo de aquecimento do grupo para entrar nos personagens do RPG era um pouco maior, algumas vezes os participantes dispersavam sua atenção da estória, outras vezes sentia dificuldades em entrar no papel de forma mais profunda para que pudesse sentir e me imaginar na situação, como consequência minha atuação como personagem era afetada e afetava também toda qualidade da experiência do RPG para o grupo. Percebo que apesar do RPG de mesa em si ser um tipo de ensaio comportamental in vitro (uso da imaginação), muitas situações demandavam que atuássemos como os personagens da estória (ensaio in vivo) necessitando que fizéssemos uso constantemente de habilidades sociais específicas. Acredito que com o uso de estímulos externos (especialmente que usam audição, olfato e visão) para auxiliar na vivência do papel serão sempre no mínimo uma proposta muito interessante a ser pensada, pois além de aquecer os participantes mais rapidamente e auxiliá-los que se aprofundem na experiência do RPG, envolve o uso constante de estímulos condicionados e consequentemente comportamentos respondentes ou reflexos como: medo, nojo, alegria, raiva, tristeza, espanto, ansiedade e uma série de outras sensações involuntárias".

Percebe-se nas respostas acima que a falta de sonorização nas partidas não só influencia na interpretação dos jogadores, mas também sobre o tempo que eles levam para sentirem-se no personagem, entrarem na estória. Além de os deixarem mais focados no jogo, como já dito, pois muitas vezes quando se jogava sem a sonorização, alguns no meio da narrativa simplesmente começava a conversar de um assunto aleatório, ou se distraiam com o celular, ou até mesmo acabavam dormindo. E nas partidas teste, percebeu-se que essas situações diminuíram bastante.

Outros questionamentos realizados com os participantes foram: em que momento a sonorização foi mais importante, em qual não fez diferença e quando acabou piorando a situação. Para a primeira questão, todos responderam que a música como background deu mais vida a estória, fazendo com que as palavras parecessem ter mais peso nos momentos decisivos, principalmente nas lutas. Já sobre em qual não 
fez diferença, apenas dois destacaram que alguns efeitos sonoros não tiveram efeito nenhum sobre eles, os outros responderam que nenhum som foi ignorado. Sobre quando acabou piorando a situação, as respostas foram divididas, 50\% afirmou que em nenhum momento se sentiu incomodado e os outros $50 \%$ descreveram que em alguns momentos os sons não combinaram com a situação, ou que roubavam a atenção da narrativa, ou que houve pausas para colocar determinado som, porém essa última foi mais no início, quando ainda estavam se acostumando.

\section{CONSIDERAÇÕES FINAIS}

Apesar de ser uma pesquisa em fase inicial, os resultados mostram que os efeitos apontam para uma maior imersão, uma vez que todos os participantes confirmaram que se sentiram mais imersos na narrativa por meio do som.

A partir dos resultados obtidos, chegou-se as seguintes conclusões; embora o som esteja mais relacionado com a imersão sensorial, de acordo com as definições teóricas, ele acabou influenciando os jogadores a sentirem-se mais imersos imaginativamente, logo por estarem mais focados no conteúdo narrativo e representativo do jogo, e também mais imersos nos desafios, quando afirmam que a música nos momentos decisivos aumentou a dramaticidade da situação dando mais vida as batalhas, por exemplo.

De todos os sons testados, o que mais teve influência nos jogadores foi a música, seguida pelos sons ambientes, pois analisando as respostas dos questionários, ela foi a mais citada, sendo a que mais teve influência positiva. Fazendo uma comparação aos filmes, seria equivalente a trilha sonora deles.

Acredita-se também que a falta de estímulos sonoros no jogo chega a dificultar a performance do jogador, afastando-o do universo que lhe é apresentado na narrativa. Nesse ponto, todas as respostas dadas pelos jogadores afirmam que sem a sonorização, a dificuldade de imaginar a situação é maior, o jogo acaba ficando de certo modo monótono e o esforço do narrador em passar a situação para eles é maior podendo até gerar interpretações erradas.

Por último, conclui-se que, para que ocorra a sonorização no RPG seria necessário ser alguém que não estivesse jogando, pois quando a observação participante foi realizada, a atenção foi dividida entre jogar e sonorizar o momento, causando alguns desconfortos em algumas situações. Diferente de quando foi realizada a observação não-participante, em que o foco estava apenas em sonorizar a partida, proporcionando uma imersão melhor aos jogadores. Uma solução para isso seria um mestre, com experiência em narrar, ficar com a tarefa de sonorizar as partidas, ou alguém de fora disposto a tal ato. Assim não haveria problemas para os jogadores de se distraírem e ter toda sua atenção voltada para a narrativa.

Além da pesquisa demonstrar que o som no RPG deixa a experiência dos jogadores mais imersiva, outra finalidade para a pesquisa seria de servir de base para futuros estudos e trabalhos na área, como, por exemplo, desenvolver aplicativos ou softwares para a sonorização de RPG de mesa, pois o mercado nessa área é um pouco escasso. 


\section{REFERÊNCIAS}

ABREU, Luanna. Design Sonoro? Brasil: Revista Cliché, 2013. Disponível na internet por http em: <http://www.revistacliche.com.br/2013/02/design-sonoro>. Acesso em 22 abril. 2016.

BERCHMANS, Tony. A música do Filme, tudo o que você gostaria de saber sobre a música de cinema. São Paulo: Escrituras, 2008.

BRATHWAITE, Brenda; SCHREIBER, lan, Challenges for Game Designer: Non-digital exercises for video game designers. Boston: Cengage Learning, 2009.

COOK Monte, TWEET Jonhathan, WILLIAN Skip. Dungeons \& Dragons: Livro do Jogador: Livro de Regras Básicas, V.3.5. São Paulo: Devir, 2004.

ERMI, Laura; MÄYRÄ, Frans. Fundamental Components of the Gameplay Experience: Analysing Immersion. Finlândia: Proceedings of DiGRA, 2005. Disponível na internet por http em: <https://www.semanticscholar.org/paper/Fundamental-Components-ofthe-Gameplay-Experience-Ermi-

M\%C3\%A4yr\%C3\%A4/281919e199e285c02bf92aab07d3d637d3c0b060/pdf>. Acesso em 22 abril. 2016

FINCH, Matthew J. Swords \& Wizardry: Regras Básicas. [S.I.]: Mythmere Games, 2009.

GERHARDT, Tatiana Engel; SILVEIRA, Denise Tolfo (Org.). Métodos de pesquisa. Porto Alegre: Ed. da UFRGS, 2009.

MURRAY, Janer H. Hamlet no Holodeck: O Futuro da Narrativa no Ciberespaço. São Paulo: UNESP, 2013.

OLIVEIRA, Gustavo Queiroz de. O jogo Black Death: uma experiência de design sonoro e design de jogos de computadores. 2002. Dissertação (Mestrado) - Universidade Estadual de Campinas, Curso de Pós-Graduação em Multimeios do Instituto de Artes São Paulo, 2002.

PAVÃO, Andréa. A aventura da leitura e da escrita entre mestres de RPG de Roleplaying Game. Rio de Janeiro: Devir, 2000.

SALES, Matheus. "RPG (Role-Playing Game)". Brasil: Brasil Escola. Disponível na internet por http em: <http://brasilescola.uol.com.br/curiosidades/rpg.htm>. Acesso em 15 abril. 2016.

SCHELL, Jesse. The Art of Game Design - A Book of Lenses. Burlington: Morgan Kaufmann Publishers, 2008.

SCHULLIAN, Dorothy M.; SCHOEN, Max. Music and Medicina. New York: Henry Schuman, 1948. 